\title{
Histomorphological study of the parathyroid gland in female Kuttanad ducks (Anas platyrhynchos domesticus)
}

\author{
Firdous Ahmad Dar, S. Maya, Jose John Chungath, N. Ashok, Harshad Sudhir Patki and K. S. Prashanth Kumar \\ College of Veterinary and Animal Sciences, Mannuthy \\ Kerala Veterinary and Animal Sciences University, Mannuthy, Thrissur, Kerala, India \\ Corresponding author: Firdous Ahmad Dar, email: drromry@gmail.com \\ Received: 19-08-2013, Revised: 28-09-2013, Accepted: 29-09-2013, Published online: 18-11-2013
}

doi: 10.14202/vetworld.2013.941-944 How to cite this article: Dar FA, Maya S, Chungath JJ, Ashok N, Patki HS and Prashanth Kumar KS (2013) Histomorphological study of the parathyroid gland in female Kuttanad ducks (Anas platyrhynchos domesticus), Veterinary World 6(11): 941-944.

\begin{abstract}
Aim: The present work was targeted to form the baseline data of normal morphological and histological picture of parathyroid gland in female Kuttanad ducks.

Materials and Methods: A Histomorphological study of the parathyroid gland was carried out in twelve adult female Kuttanad ducks (Anas platyrhynchos domesticus) of 20 weeks of age. Birds reared semintensively were procured from Kerala Veterinary and Animal Sciences University Poultry and Duck Farm and sacrificed humanely. Glands were collected and gross parameters were recorded. The glands were fixed in 10 percent neutral buffered formalin. The small sized glands were processed as such by routine histological methods, paraffin blocks were prepared and sectioned to a thickness of $5 \mu$. The tissues were stained by Haematoxylin and Eosin $(\mathrm{H} \& \mathrm{E})$ for routine histological studies and Gomori's rapid one step trichrome method for connective tissue fibres. Micrometric parameters were recorded using ocular micrometer.
\end{abstract}

Results: Parathyroid glands in Kuttanad ducks lay just caudal to the division of the innominate artery into the subclavian and common carotid arteries. Parathyroids were oval to spherical in shape, yellow in colour and smaller than thyroid gland of the representative sides. The arterial blood supply was from common carotid artery and blood from gland was drained directly into jugular vein. Although it lied close to the thyroid, thymus and ultimobranchial gland, parathyroid tissue did not merge to any of the above mentioned three glands. Parenchyma was composed irregular anatomizing cords of cells supplied by connective tissue stroma penetrated by blood capillaries. Parenchyma was predominantly made of lightly stained cell, the chief cell. The nuclei were round and contain one or two nucleoli. Oxyphil cells present in parathyroid glands of other mammals were not seen in the present study.

Conclusion: Histomorphological features or characteristics of Parathyroid gland in Kuttanad duck were studied. Cranial parathyroids were larger in size as compared to the caudal parathyroids. Parathyroid glands were enclosed by a welldeveloped connective tissue capsule made predominantly of collagen fibers. Parenchyma was composed of irregular anatomizing cords of cells supplied by connective tissue stroma and penetrated by blood capillaries. Oxyphil cells were absent similar to other aves. Parathyroid gland is very vital in maintaining the homeostasis of the plasma calciumReference?. Findings of this study will contribute to the anatomy literature as a valuable resource for future researchers focused on this subject and will also help other allied subjects on comparative basis.

Key words: chief cells, Kuttanad, parathyroid

\section{I ntroduction}

Calcium is essential for normal metabolic processes in birds. Several hormonal systems exist to regulate calcium levels in the body. Most important glands involved in avian calcium regulation are Parathyroid (PTG) and Ultimobranchial glands (UBG). Calcium disorders can lead to a variety of clinical problems in birds. The major physiological stimulus for parathyroid hormone secretion from the chief cells is a fall in plasma calcium concentration; while a rise in calcium suppresses it [1]. The hormone with the greatest involvement in calcium regulation in birds is parathyroid hormone, with calcitonin playing a minor and uncertain role [2]. The parathyroid chief cells undergo morphologic changes corresponding to different stages

Copyright: The authors. This article is an open access article licensed under the terms of the Creative Commons Attribution License (http://creativecommons.org/licenses/by/2.0) which permits unrestricted use, distribution and reproduction in any medium, provided the work is properly cited. of the secretory cycle [3]. Parathyroid cells in most animals store relatively small amounts of preformed hormone but are capable of responding to minor fluctuations in calcium ion concentration by rapidly altering the rate of hormonal synthesis and secretion [4].

Kuttanad ducks native to Kerala are considered as highly efficient in terms of egg production and egg size and are widely considered as an ideal layer duck breed successfully launched in many other states of India. There exists a paucity of data with regards to duck parathyroid gland in general and that of Kuttanad duck in particular. Thus, our present work is targeted to give a normal morphological and histological picture of parathyroid gland which will serve as a platform for the allied disciplines to differentiate any deviations from normal. It can be further used for comparative studies of parathyroid gland between different species as well as breeds of domesticated and wild ducks. 


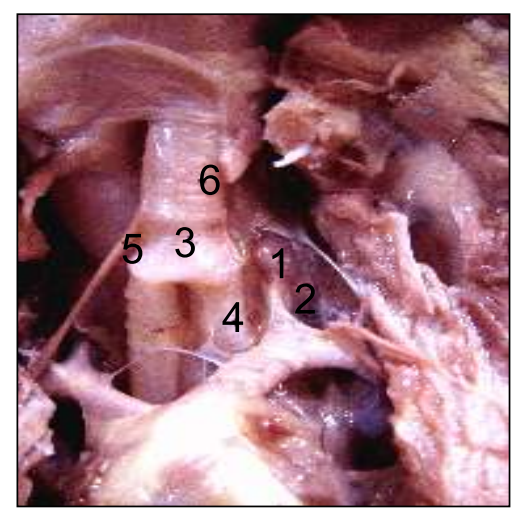

Fig. 1 I nsitu position of parathyroid gland in Adult female Kuttanad duck. 1. Thyroid gland, 2. Parathyroid gland, 3. Syrinx, 4. Extrapulmonary primary bronchi, 5. Sternotrachealis muscle, 6 . Trachea

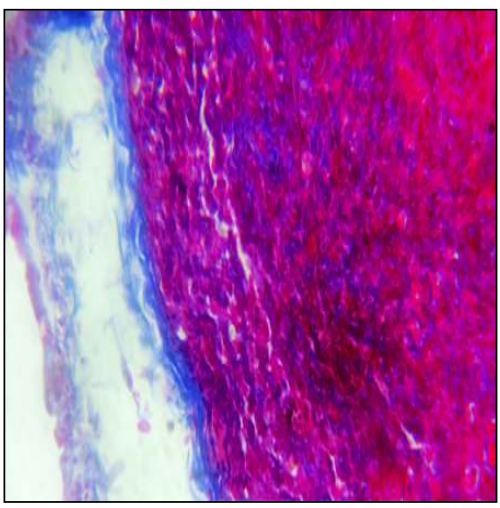

Fig. 4. Cross section of parathyroid gland showing capsule predo-minantly made of
collagen. Gomori's rapid one step Trichrome - 40X

\section{Materials and Methods}

Ethical approval: Since the present work was done in parallel with work on the thyroid gland, the same healthy birds were utilized for sample collection as sanctioned by Animal ethics committee with sanction order IAEC-12-08 with humane view to limit the use of total number of birds for the study.

Histomorphological studies on parathyroid gland were carried out in twelve adult female Kuttanad ducks (Anas platyrhynchos domesticus) of 20 weeks of age. Birds reared semintensively were procured from Kerala Veterinary and Animal Sciences University Poultry and Duck Farm and sacrificed humanely. Glands were collected and gross parameters like length and breadth were taken by Vernier's caliper. Weights of parathyroid glands were taken by Digital weighing balance (Shimadzu- ELB 300). After recording the morphometric parameters, the glands were fixed in 10 percent neutral buffered formalin. The small sized glands were processed as such by routine histological methods, paraffin blocks were prepared and sectioned to a thickness of $5 \mu$. The tissues were stained by Haematoxylin and Eosin (H\&E) for routine histological studies and Gomori's rapid one step trichrome method for connective tissue fibres [5]. Using Olympus 16 mega pixel digital camera macroscopic and microscopic findings were recorded. Micrometric parameters were

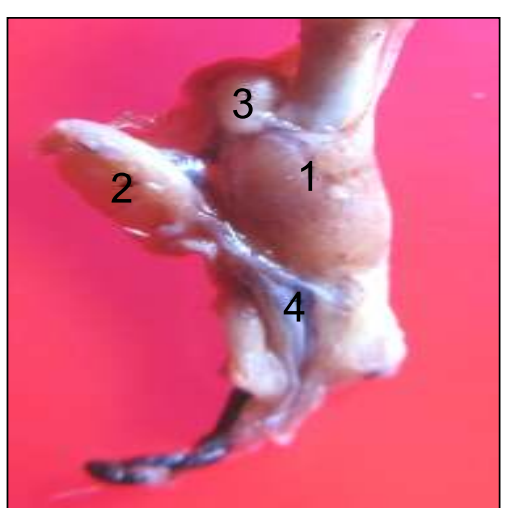

Fig. 3. Topography of parathyroid gland 1. Thyroid gland, 2. Parathyroid gland, 3. Ultimobrancheal gland, 4. Jugular vein

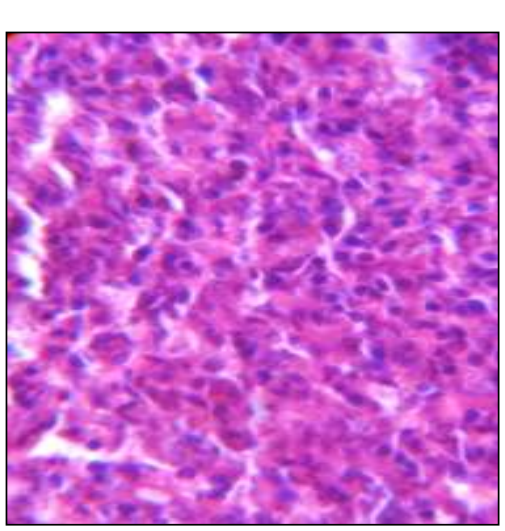

Fig. 6. Parenchyma of parathyroid gland, composed predominantly chief cells $\mathrm{H} \& \mathrm{E}$. 100X recorded using ocular micrometer. Nomina Anatomica Avium was used for nomenclature [6].

\section{Results}

In female Kuttanad ducks, the paired parathyroid glands lay just caudal to the division of the innominate artery into the subclavian and common carotid arteries. Lying in contact with the thyroid at or near the posterior pole, parathyroids were oval to spherical in shape, yellow in colour and smaller than thyroid gland of the representative sides (Fig. 1). The length, breadth, and thickness of the cranial parathyroid glands were approximately $1.92 \pm 0.3 \mathrm{~mm}, 1.4 \pm 0.3 \mathrm{~mm}$ and $1.1 \pm$ $0.4 \mathrm{~mm}$, respectively; whereas, the corresponding parameters of the caudal parathyroid glands were 1.13 $\pm 0.23 \mathrm{~mm}, 0.94 \pm 0.21 \mathrm{~mm}$ and $0.59 \pm 0.16 \mathrm{~mm}$, respectively. The arterial blood supply was from parathyroid arteries which branched out from the common carotid artery and blood from gland was drained directly into jugular vein (Fig. 2). Although it lied close to the thyroid, thymus and ultimobranchial gland, parathyroid tissue did not merge to any of the above mentioned three glands (Fig. 3).

Histologically, Parathyroid glands were enclosed by a well-developed connective tissue capsule made of predominant collagen fibers with some elastic and reticular fibers (Fig. 4). From the capsule fine connective tissue trabaculae extended inwards constituting stroma 
of the gland (Fig. 5). Arteries which supplied parathyroid gland entered the fibrous capsule at different angles.

Parenchyma of the parathyroid gland was composed of irregular anatomizing cords of cells supplied by connective tissue stroma penetrated by blood capillaries. Parenchyma was predominantly made of lightly stained cells, the chief cells (Fig. 6). The shapes of the chief cells were cuboidal and measured 16-20 $\mu \mathrm{m}$ along their longitudinal axis. The parenchymal cells were separated from adjacent blood capillaries by a relatively thick basal lamina. The nuclei were round with approximately $4 \mu \mathrm{m}$ in diameter and contain one or two nucleoli. Oxyphil cells, as present in parathyroid glands of other mammals were not seen in present study.

\section{Discussion}

In birds, the regulation of calcium and phosphate homeostasis was typically mammalian with only minor differences [7]. Number of parathyroid glands varied between two and four in birds. In chicken there were two pairs of parathyroid glands often fused together located slightly caudal to the thyroid, whereas only one pair was found in the Japanese quail $[8,9,10]$. In mice, there was only one pair of parathyroid glands developed with the thymus from the endoderm of 3rd pharyngeal pouch at the beginning which was homologous to inferior parathyroid glands in humans [11-13]. Accessory parathyroid tissues had been reported in adjacent areas in birds, included within the thyroid, thymus and ultimobranchial gland [14-16]. In Falconiformes, the parathyroid glands were supplied by one to three parathyroid arteries. The average number of thyroid and parathyroid arteries in common buzzard was significantly higher than those in common kestrel [17].

In Kuttanad ducks, paired parathyroid glands lay just caudal to the division of the innominate artery supplied by three arteries and drained by jugular vein. No accessory parathyroid glands were seen that were closely associated with thyroid, thymus and ultimobranchial glands. Cranial parathyroids were larger in size as compared to caudal parathyroids. However, cranial as well as caudal parathyroids showed strong similarity in their microanatomy. Parathyroid gland was seen attached to the thyroid gland and the capsule of the thyroid gland was continuous with that of the parathyroid. The arterial blood supply came from parathyroid arteries which branched out from the common carotid artery and blood from the gland drained directly into jugular vein. Parenchyma was composed predominantly of lightly stained chief cells arranged in irregular cords towards the periphery and densely packed towards center.

In mouse, parathyroids were surrounded by a thin, loose capsule. The trabaculae from the capsule entered the parenchyma and followed the capillaries within the gland [18]. The parathyroid arteries, 1-2 in number, originated from the caudal thyroid artery and got separated from the later under the fibrous capsule of the glandular cluster in budgerigar [19]. Irregular anatomizing cords of cells separated by connective tissue stroma were reported in laying hens [20]. Parenchyma of parathyroid gland was composed of a single cell type in chicken [21]. In humans, chief cells undergo morphologic changes corresponding to different stages of the secretory cycle. The oxyphil cells of the parathyroid gland derived from chief cells on aging and due to some metabolic derangements have the potential to produce parathormone (PTH), PTH -related protein, and calcitriol. However, Oxyphil cells were reported to be absent in the avian parathyroid gland [22] .

The hypercalcemic effects of PTH were greater in egg laying hens than in cockerels. The fact may be attributed either calcium binding by yolk proteins in the plasma or to the presence of additional PTH receptors in medullary bone and oviduct. The major physiological stimulus for PTH secretion from the chief cells was a fall in plasma calcium concentration, while a rise in plasma calcium suppressed the hormone secretion [23].

\section{Conclusion}

Histomorphological features of Parathyroid gland in female Kuttanad duck were documented. Cranial parathyroids were larger in size as compared to the caudal parathyroids. However, cranial as well as caudal parathyroids showed strong similarity in their microanatomy. Parenchyma of the parathyroid gland was composed of irregular anatomizing cords of cells supplied by connective tissue stroma penetrated by blood capillaries. Oxyphil cells were absent similar to other aves. Parathyroid gland is very vital in maintaining the homeostasis of the plasma calcium. Both hypo and hypercalcemic condition affect the body growth and production potential of the birds. Findings of this study will contribute to the anatomy literature as a valuable resource for future researchers focused on this subject and will also help other allied subjects on comparative basis.

\section{Authors' contributions}

FAD-identification of parathyroid gland, morphology, tissue processing, staining, histological observations and interpretations of results. SM-the present work was done under the guidance of S. Maya, contributed to experimental protocol and correction of draft. JJC- As the head of the department provided facilities to conduct this work and contributed to preparation of final draft. NA- timely corrections of the draft and valuable suggestions. HSP- contributed to collection of literature. KSPK- contributed to tissue processing, staining and photography.

\section{Acknowledgements}

The authors are highly thankful to the Dean, College of Veterinary And Animal Sciences, Mannuthy, Kerala, India for providing the funds and facilities to carry this work.

\section{Competing interests}

The authors declare that they have no competing interests. 


\section{References}

1. Brown, E. (1991) Extracellular Ca2+ sensing, regulation of parathyroid cell function and role of $\mathrm{Ca} 2+$ and other ions as extracellular (first) messengers.Physiol. Revs. 71:371-411.

2. Ricardo de Matos (2008) Calcium Metabolism in Birds.Veterinary Clinics of North America: Exotic Animal Practice.Endocrinol. 11 (1): 59-82.

3. Huayue, C., Takao, S., Shoichi, E. and Kinya, K. (2013) An Update on the Structure of the Parathyroid Gland.The Open Anatomy Journal. 5: 1-9.

4. Capen, C. C. and Rosol, T. J. (1989) Recent advances in the structure and function of the parathyroid gland in animals and the effects of xenobiotics.Toxicol Pathol. 17(2):333-45.

5. Luna, L. G. (1968) Manual of Histological Staining Methods of the Armed Forces Institute of Pathology. 3rd edition. McGraw-Hill BookCompany, New York, 258p.

6. Baumel, J. J., King, A. S., Breazile, J. E., Evans, H. E. and Vanden Berge, J. C. (1993) Nomina Anatomica Avium. MA: Nuttall Ornithological Club, Cambridge.

7. Norris, D. O. (2007) Vertebrate Endocrinology. 4th edn. Academic Press. pp: 507-508.

8. Dacke, C. G. (1979) Parathyroid hormone and eggshell calcification in Japanese quail. J. Endocrinol., 71: 239-243.

9. Clark, N. B. and Sassayama, Y. (1981) The role of parathyroid hormone on renal excretion of calcium and phosphate in the Japanese quail. Gen. Com. Endocrinol. 43: 234-241.

10. Kenny, A. D. (1986) Parathyroid and ultimobranchial glandsIn. In:"Avian Physiology", 4th ed. Springer Verlag. New York.,pp: 466-478.

11. Carlson, D. (2010) Parathyroid pathology: hyper parathyroidism and parathyroid tumors. Arch Pathol. Lab Med.134: 1639-44.

12. Sheffield, E. A. (2002) An approach to common pathological conditions in the parathyroid glands. CPD Cell Pathol.4: $135-8$.
13. Moore-Scott, B. A. and Manley, N. R. (2005) Differential expression of Sonic hedgehog along the anterior-posterior axis regulates patterning of pharyngeal pouch endoderm and pharyngeal endoderm-derived organs. Dev Biol. 278: 32335.

14. Swarup, K. and Das, V. K. (1974) The ultmobranchial, body of Pied myna, Sturnus contra (Linn.) Arch. Anat. Microsc. 63: 203-215.

15. Belanger, L. F. (1971) The ultimobranchial gland of birds and the effects of nutritional variations. J Exp Zool.178:125130.

16. Dhande, R. R., Suryawanshi, S. A. and Pandey, A. K. (2006) Seasonal changes in plasma calcium and inorganic phosphate levels in relation to parathyroid structure of the grey quail, Ccoturnix coturnix Linnaeus. J Environ Biol. 27 (1):123-128.

17. Radek, T. and Piasecki, T. (2007) Topography and arterial supply of the thyroid and the parathyroid glands in selected species of Falconiformes. Anat. Histol. Embryol. 36(4):241-9.

18. Parviz, M. P., Shafgat, R. Q. and Shahrokh, S. (1993) Anatomy, Histology, Ultrastructure, Parathyroid, Mouse. In: Endocrine System. Springer Berlin Heidelberg.252-257.

19. Radek, T. and Piasecki, T. (2004) The topographical anatomy and arterial supply of the thyroid and parathyroid glands in the budgerigar (Melopsittacusundulatus). Folia Morphol (Warsz). 63(2):163-71.

20. Nevalainen, T. (1969) Fine structure of the parathyroid gland of the laying hen (Gallus domesticus).Gen. Comp. Endocrinol. 12: 561-567.

21. Ali, P. and Rahmat, A. F. D. (2011) Morphometrical Evaluation of Parathyroid Aland in Native Chickens. 2nd International Conference on Agricultural and Animal Science vol.22.

22. Hodges, R. D. (1974) The Histology of the Fowl. Academic Press, London, 648p.

23. Wittow, G. C. (2000) Sturkie's Avian Physiology, 5th ed. London: Academic Press. pp: 473-48. 